\title{
Personality Traits and Excessive Computer and Internet Usage: A Robust Relation?
}

\author{
Dr. Nikolaos Tsigilis \\ Department of Journalisms and Mass Media, Aristotle University of Thessaloniki \\ 46 Egnatia Ave, 54625, Thessaloniki, Greece \\ E-mail: ntsigilis@jour.auth.gr
}

Received: April 17, 2019 Accepted: May 10, 2019 Published: May 30, 2019

doi:10.5296/ijssr.v7i2.14676 URL: http://dx.doi.org/10.5296/ijssr.v7i2.14676

\begin{abstract}
Previous studies on the association between personality traits and computer and/or internet addiction reported mixed results. Moreover, whereas some authors claim that personality traits measures have adequate level of convergent validity (Hong et al., 2008; Paunonen, 2003), recent meta-analysis seems to seriously question it (Pace \& Brannick, 2010). The aim of the present study was to examine whether personality traits can reliably predict excessive computer and internet usage in a consistent way and irrespectively of the personality traits measure used. Two hundred and thirty university students voluntarily participated in the study. They provided responses to various instruments including the Big Five Inventory, the International Personality Item Pool, the Computer Addiction Test and Internet usage. Canonical correlation analysis was used to examine the similarity between the two personality traits measures. Results showed that there is $50 \%$ of unexplained variance between the two personality measures. Multiple regression analyses (linear or ordinal depending on the nature of the criterion variable) showed that the pattern and strength of predictions seems to fluctuate in relation to the personality traits instrument used. In most cases conscientiousness and agreeableness were revealed as important personality traits to understand technological addictive behaviors. Researchers should be aware of the possible fluctuations in findings when they study the effect of personality traits on computer and excessive internet use.
\end{abstract}

Keywords: Internet addiction, Personality traits, Canonical correlation, Convergent validity 


\section{Introduction}

In post-modern society, a paramount change in leisure practices, interpersonal communication, and relationship formation was caused by the evolution of technology. New forms of self-with-other representation and new possibilities to freely access information have emerged. Since the personal computer first appeared, it became a vital part of modern human life. Nowadays, people use computer technology to play games, communicate with others, relieve stress and boredom, entertain themselves, and pass their time (Carpenter \& Buday, 2007; Doherty, 2002). Despite the myriad of uses and many benefits that a computer provides, abuse also occurs, with some peoples' use of the computer being described as "compulsive" or even "addictive" (Griffiths, 1995).

Although some researchers propose that the term "addiction" should be applied only to cases involving chemical substances (Bratter \& Forrest, 1985), others have linked technological addictions to impulse control disorders (Shapira, Goldsmith, Keck, Khosla, \& McElroy, 2000; Young, 1998). Specifically, Griffiths (1995) operationally defined technological addictions as "...(nonchemical) behavioral addictions which involve human-machine interaction" (p. 15). Additionally, he proposed that these nonchemical addictions can be divided into passive (e.g. television) and active (e.g. computer games) and may contain addictive behaviors located under other types of addictions (Griffiths, 1995).

In light of the fact that the internet provides a user-friendly environment with access to available information, a wide range of users are now online. As a result, the range of people who use and may misuse computers is wider than ever before. The earliest empirical research study that addressed the question of whether or not the internet can be characterized as addictive was carried out by Young (1996), who investigated the existence of internet addiction and the degree of problems caused by its use. Since then, there have been a growing number of academic studies investigating the excessive use of the internet focusing on case studies of excessive internet users (Griffiths, 2000) or exploring the relationship between internet users and non-excessive users with other psychiatric problems (Andreassen et al., 2016; Shapira et al., 2000). With millions of users worldwide, a question is raised concerning what types of people use the computer and the internet in an excessive way and how other behaviors may interact with the users' personality traits.

Many researchers propose that personality-based variations in behavior can be described in terms of the Big Five factors of personality (Costa \& McCrae, 1992; Goldberg, 1990; John \& Sriviasta, 1999). These factors, known as extraversion, neuroticism (or its counterpart emotional stability), openness to experience (or intellect), agreeableness, and conscientiousness, represent relatively enduring patterns of thought, emotion, and behavior that are stable across a wide variety of different situations (Caspi \& Roberts, 1999) and over time (Digman, 1989).

Recently, as the popularity of computer and internet use is rapidly increasing, it is suggested that this area is worthwhile to be investigated from a personality perspective, especially since levels of computer or internet usage is often described as excessive or even problematic. Indeed, previous research activity attempted to understand the various factors that contribute 
to technological addictive behaviors (e.g. computer, internet, social media addiction) focusing on the effect of personality traits as an antecedent factor. By using different questionnaires and personality adjective rating scales, research findings suggest that individual's type of personality may be linked to levels of computer and internet excessive use or addiction (Buffardi \& Campbell 2008; Gombor \& Vas, 2008; Landers \& Lounsbury, 2006; Tsai et al., 2009).

More specifically, openness to experience, which characterizes people who are intellectual curious, imaginative, and emotionally sensitive, was positively related to the excessive use of both the computer and the internet. For example, Web sites owners (Marcus, Machilek, \& Schütz, 2006), and online gamers (Teng, 2008) reported higher scores of this factor. Similar results have also been obtained for people who score high on extraversion (sociable, talkative, and active) (Teng, 2008; Wang, Ho, Chan, \& Tse, 2015). However, these findings are not consistent across studies and seem to differentiate depending on the specific internet addition behavior examined (e.g. Wang et al., 2015). Neuroticism, that describes an individual's propensity to feel fear, anxious, and other negative emotions, was related to excessive internet usage, as people high in neuroticism were more likely to frequently use both social networking sites (SNS) (Wang et al., 2015) and instant messaging (Ehrenberg, Juckes, White, $\&$ Walsh, 2008). The other two personality traits (agreeableness and conscientiousness) have shown mixed results. Whereas conscientiousness was found to be a significant predictor of internet and game addition (Wang et al., 2015) results on agreeableness seem to be fluctuated (e.g. Landers \& Lounsbury, 2006; Wang et al., 2015). For example, in the study of Landers and Lounsbur (2006) agreeableness was associated with internet usage. In another study however (Wang et al., 2015), agreeableness did not predict any of three examined internet addictions (internet, game and social networking). Taking into account the contradictory findings, further research activity is warranted to better understand the association between Big Five traits and technological addictive behaviors (e.g. computer and Internet excessive use) and the effects of the specific instrument used to measure personality traits.

\subsection{Aim and Hypotheses}

The present study had two primary purposes. The first was focused on the role of personality traits as significant predictors of computer and excessive internet use in a Greek university student sample. Towards this end two widely used personality traits instruments were employed. The second purpose was to investigate whether prediction of excessive usage of computer and internet is independent of the personality traits instrument used, providing thus evidence of their robust association.

Based on previous research indicating that personality is associated with the excessive use of the technology (Buffardi \& Campbell 2008; Landers \& Lounsbury, 2006; Teng, 2008; Wang et al., 2015), the following hypothesis was set for further investigation.

Hypothesis 1: Certain personality traits will be related to the excessive usage of the computer and internet.

Moreover, previous studies have shown that Big Five factors irrespectively of the selected 
questionnaire can predict various behaviors (Hong, Paunonen, \& Slade, 2008; Paunonen \& Ashton, 2001; Paunonen, 2003). Specifically, Paunonen (2003), by using three different measures of the Big Five concluded that there is a strong convergence in Big Five measurements and predictions across 27 various criteria behaviors (e.g. alcohol consumption, tobacco consumption, and participation in sports). Likewise, Hong et al. (2008) who replicated Paunonen's (2003) study proposed that personality traits underlying different Big Five assessments have important criterion related validities. Despite, however the above-mentioned studies, a recent meta-analysis found low levels of agreement among the personality traits of four different measures (Pace \& Brannick, 2010). Given that a large number of studies was analyzed (79 usable sources) the following hypothesis relied on this meta-analysis study.

Hypothesis 2: The strength of excessive usage of the computer and internet prediction will be affected by the specific personality traits instrument used.

\section{Method}

\subsection{Participants}

In the present study 230 Greek university students from the Aristotle University of Thessaloniki participated. Participants were from different social sciences schools $(60.2 \%$ Journalism and Mass Media Communication; 18.4\% Primary Education; 21.4\% other faculties) and their ages ranged from 18 to 48 years old $(M=23.99, S D=6.77 ; 84.9 \%$ females).

\subsection{Instruments}

Personality traits were assessed using two questionnaires: (i) Big Five Inventory (BFI; John \& Sriviasta, 1999) and (ii) International Personality Item Pool (IPIP; Goldberg et al., 2006). These instruments were selected because they are widely used inventories showing that their underling constructs relate to various behavioral criteria in various applied fields (e.g. Fossati, Borroni, Marchione, \& Maffei 2011; Pace \& Brannick, 2010).

\subsubsection{BFI}

The BFI comprises 44 items for assessing five personality traits. Using a five-point scale $(1=$ strongly disagree, $5=$ strongly agree), respondents are asked to rate the degree to which they perceive themselves as a person who engages in a variety of affective, behavioral, and cognitive responses. This questionnaire was recently adapted to the Greek cultural context (Baltzis, Manolika, \& Gardikiotis, 2012).

\subsubsection{IPIP}

The IPIP questionnaire which was adapted to Greek by Ypofanti et al. (2015) consists of 50-items assessing five personality traits, Conscientiousness, Emotional Stability/ Neuroticism, Intellect, Agreeableness and Extraversion. Participants rated how well each IPIP item describes them on a 5 -point Likert scale $(1=$ very inaccurate, $5=$ very accurate $)$. Greek version of IPIP verified the correlated five factor structure with good internal consistencies $(\alpha$ 
$=.758-.875)$.

\subsubsection{Computer Addiction}

The excessive use of the computer was assessed by the Computer Addiction Test which was adapted to Greek cultural setting by Siomos, Floros, Mouzas, and Angelopoulos (2009). This test comprises 20 items which are scored on a five-point Likert scale ( $1=$ never, $5=$ always). The minimum score is 20 (no tendency to computer addiction) and the maximum is 100 (high tendency to computer addiction). Siomos et al. (2009) findings showed the instrument's satisfactory test-retest reliability, internal consistency and construct validity.

\subsubsection{Internet Usage}

Based on previous research (Landers \& Lounsbury, 2006), internet usage was measured as a self-report item on a four-point scale with response choices as follows: (1) less than 1 hour per day, (2) between 1 and 2 hours per day, (3) between 2 and 4 hours per day and (4) more than 4 hours per day.

\subsection{Procedure}

Participants were instructed to read the purpose of the study and then complete the questionnaires voluntarily before or at the end of the class. The order of instruments assessing personality traits was counterbalanced so that half of the sample initially completed the BFI, followed by the Computer Addiction Test, the Internet use, and finally the IPIP. The other half completed the IPIP first, followed by the Computer Addiction Test, the Internet use, and finally the BFI. Given the length of the questionnaires, the survey took up to 15 minutes for participants to complete.

\subsection{Data Analysis Strategy}

Instruments' factorial structure was examined using exploratory factor analysis with oblimin rotation. Items loading above .30 were considered statistically significant. Internal consistency of the derived factors was assessed employing Cronbach's $\alpha$. Given that both personality questionnaires measure multidimentional concepts canonical correlation analysis was conducted to examine their convergent validity. Finally, multiple regression analysis (linear and ordinal depending on the nature of the outcome variable) was performed to test whether personality traits could reliably predict technological addition. Overall four analyses were conducted, one for each assessment of technological addition and personality traits measure.

\section{Results}

\subsection{Instrument’s Factorial Structure}

\subsubsection{BFI}

Factor analysis of the BFI responses revealed five factors with eigenvalues above unity, explaining $49.5 \%$ of the variance in the data. All factor loadings were well above .30 . Moreover, internal consistency of the Openness, Neuroticism and Extraversion were 
satisfactory $(.788, .753, .724$ respectively), whereas $\alpha$ values for Agreeableness, and Conscientiousness were acceptable (.667 and .674 respectively).

\subsubsection{IPIP}

Similar analysis to IPIP responses showed that five factors should be retained, explaining $50.55 \%$ of the variance. All item loadings to their respective factors were considered statistically significant (>.30). Factors' $\alpha$ values were satisfactory (.801-.726), apart from Conscientiousness which was acceptable (.664).

\subsubsection{Computer Addiction}

Results concerning Computer Addiction Test revealed one dimension, explaining 35.56\% of the variance. Items loadings were ranging from .353 to .704 . In addition, internal consistency was satisfactory $(\alpha=.889)$.

\subsection{Canonical Correlation Analysis}

Canonical Correlation Analysis (CCA) was employed to examine the multivariate relationship between the set of BFI and the set IPIP factors. Results showed five statistically significant functions with squared canonical correlation coefficients $\left(\mathrm{R}_{\mathrm{c}}{ }^{2}\right)$ for each successive function (see Table 1). Collectively, the full model across all functions was statistically significant using the Wilks's $\lambda=.036$ criterion, $F(25,818.77)=47.385, p<.001$ with an effect size of $1-\lambda=.964$, thus explaining $96.4 \%$ of the total shared variance between the canonical variates (Sherry \& Henson, 2005). Given the effects of each function, all functions were considered noteworthy in the context of this study (squared canonical correlation $71.2 \%$, $57.1 \%, 47.2 \%, 26.9 \%, 24.5 \%$ for each consecutive function).

Table 1. Canonical Correlation Analysis Results between BFI and IPIP

\begin{tabular}{lcccc}
\hline Roots & $\mathrm{R}_{\mathrm{c}}$ & $\mathrm{R}_{\mathrm{c}}{ }^{2}$ & $\begin{array}{c}\text { \% variance in IPIP } \\
\text { explained by BFI }\end{array}$ & $\begin{array}{c}\text { \% variance in BFI } \\
\text { explained by IPIP }\end{array}$ \\
\hline $1-5$ & $.766^{*}$ & .587 & 16.7 & 16.4 \\
$2-5$ & $.713^{*}$ & .509 & 10.6 & 9.6 \\
$3-5$ & $546^{*}$ & .298 & 4.5 & 4.6 \\
$4-5$ & $.480^{*}$ & .231 & 4.3 & 4.2 \\
5 & $.383^{*}$ & .147 & 2.5 & 2.9 \\
Total & & & 38.6 & 37.7 \\
\hline
\end{tabular}

Notes. $\mathrm{R}_{\mathrm{c}}=$ Canonical correlation. $\mathrm{R}_{\mathrm{c}}{ }^{2}=$ Squared canonical correlation, $* p<.01$.

The strength of the relationship between the two sets of variables was assessed using the redundancy index (Stewart \& Love, 1968). This statistic indicated that $48.26 \%$ of the variance in the IPIP variables was accounted for by the BFI variate. Conversely, $49.62 \%$ percent of the variance in the BFI variables was explained by the IPIP variate. 


\subsection{Regression analyses}

Next, multiple regression analysis was used to examine which personality traits are associated with the two behavior criteria. Overall, the results revealed that BFI factors accounted for $15.4 \%$ of the variance in computer excessive use, $F(5,224)=8.15, p<0.001$, whereas IPIP factors explained $16.9 \%$ of the same criterion behavior variance $F(5,224)=$ 9.09, $p<0.001$. Agreeableness and Conscientiousness were significant predictors of excessive computer use irrespectively of the personality instrument used (Table 2). When however, the IPIP personality traits were used as explanatory variables Emotional Stability was also revealed as a statistically significant predictor.

Table 2. Regression analysis results (linear and ordinal) predicting computer and internet usage from BFI and IPIP

\begin{tabular}{lcccccc}
\hline Criterion & \multicolumn{2}{c}{ Computer usage } & \multicolumn{4}{c}{ Internet usage } \\
& $\mathrm{b}$ & Part & $\mathrm{R}^{2}$ & Log-Odds & Odds & Pseudo ${ }^{2}$ \\
\cline { 2 - 7 } \multicolumn{1}{c}{$B F I$} & & & $.154^{*}$ & & & .035 \\
Agreeableness & $-.191^{*}$ & -.180 & & -.123 & .884 & \\
Conscientiousness & $-.246^{*}$ & -.240 & & $-.395^{\mathrm{a}}$ & .674 & \\
Extraversion & -.098 & -.094 & & .189 & .828 & \\
Neuroticism & .095 & .087 & & .194 & 1.214 & \\
Openness/Intellect & -.006 & -.006 & & -.006 & .994 & $.135^{*}$ \\
$\quad$ & & & $.169^{*}$ & & & \\
IPIP & $-.142^{*}$ & -.136 & & .012 & 1.012 & \\
Agreeableness & $-.273^{*}$ & -.270 & & $-.909^{*}$ & .403 & \\
Exscientiousness & -.096 & -.089 & & .108 & 1.114 & \\
Extraversion & $-.184^{*}$ & -.177 & & $.359^{*}$ & 1.431 & \\
Openness/Intellect & $.064^{\mathrm{a}}$ & .060 & & $.497^{*}$ & 1.644 & \\
\hline
\end{tabular}

Notes. Part $=$ semi-partial correlation, ${ }^{\mathrm{a}} p<.10,{ }^{*} p<.05$.

Given that Internet usage was assessed on an ordinal scale the most appropriate statistical technique was ordinal regression analysis. Results showed that none of the BFI personality traits significantly predicted levels of Internet usage, $\chi^{2}(5)=7.285, p=.200$. On the other hand, the combination of IPIP personality traits significantly predicted $13.5 \%$ (Nagelkerke's Pseudo $R^{2}=.135$ ) of the Interne usage variability, $\chi^{2}(5)=29.709, p<.001$. Three out of the five IPIP subscales were significant predictors, namely and Conscientiousness (Wald's $\chi^{2}(1)$ $=18.73, p<.001$ ), Openness/Intellect (Wald's $\chi^{2}(1)=4.81, p=.028$ ), and Emotional Stability (Wald's $\left.\chi^{2}(1)=4.35, p=.037\right)$ (Table 2).

\section{Discussion}

The first purpose of this study was to explore whether personality traits of young adults can reliably predict addictive tendencies towards excessive computer and internet use, despite the employed measure. Applying two different measures of personality, which are well known 
and widely used, the current study showed mixed results. In particular, both BFI and IPIP predicted a similar percent of computer usage variance. Two BFI personality traits (Agreeableness and Conscientiousness) and three IPIP personality traits (Agreeableness, Conscientiousness and Emotional Stability) were related to the excessive use of the computer. Agreeableness and conscientiousness were common predictors for both personality traits measures. Standardized regression coefficients as well as part-correlations suggest that conscientiousness is a stronger predictor in comparison to agreeableness. Similar findings were reported in past research (Buckner, Castille, \& Sheets, 2012; Glass, Li \& Pan, 2015; Hong et al., 2008; Paunonen, 2003).

In addition, the negative linkage of agreeableness and conscientiousness with excessive computer usage points out that they can function as protective features in terms of computer addiction. These two personality traits were also found to be significant predictors of other potentially addictive behaviors such as alcohol and tobacco use (Hong et al., 2008; Paunonen, 2003). Our findings, combined with prior studies, provide evidence to speculate that agreeableness and conscientiousness might be core predictors of addictive behaviors.

However, even though the same two personality traits (Agreeableness and Conscientiousness) were associated with excessive computer usage, emotional stability also emerged as a significant predictor only when the IPIP measure was employed. Emotional stability's unique contribution was meaningful and stronger in comparison to agreeableness. If these findings are replicated in future studies, they suggest that researchers may reach different conclusions on which personality traits affect addictive behaviors towards excessive computer usage and their different impact based on the specific instrument used.

With regard to internet use, none of the BFI personality traits was revealed as a significant predictor. On the other hand, two IPIP traits (Emotional Stability and Conscientiousness) were found to be significant predictors of the excessive use of the internet. Therefore, people who are emotionally stable and conscious tend to spend less time online. These results support previous studies showing that lower levels of emotional stability were related to excessive internet use (Yan, Li, \& Sui, 2014), greater instant messaging use (Ehrenberg et al., 2008), and a greater possibility of blogging (Guadagno, Okdie, \& Eno, 2008). In addition, conscientiousness has been found to be related negatively to excessive use of online gaming (Wang et al., 2015), SNS (Glass et al., 2014; Wilson, Fornasier, \& White, 2010) and the internet (Landers \& Lounsbury, 2006). Taking into account that less emotionally stable individuals often feel sad and cannot manage stress well, a possible explanation is that they spend more time on the internet in order to cope with stress or seek support and company (Gombor \& Vas, 2008). On the other hand, individuals who score low on conscientiousness may spend more time online to distract themselves and escape from their responsibilities.

Another notable finding of the present study was that both linear and ordinal regression analysis consistently showed that conscientiousness was the strongest predictor of computer and internet usage, irrespectively of the selected personality trait measure. The only exception was noticed on the ordinal regression of internet use on the BFI factors, in which conscientiousness was statistically significant at the .10 . This finding is in line with a recent 
meta-analysis of 12 selected studies which reported that conscientiousness showed the largest effect size among the five personality traits (Kayiş et al., 2016). Thus, development of intervention programs for preventing computer and internet addiction should primarily focus on enhancing participants self-discipline, sense of duty and their motivation to fight for success (Costa \& McCrae, 1992).

A strength of the present study was the employment of the canonical correlation analysis to examine the multivariate relationship between the two personality traits measures. To the best of our knowledge prior studies which used more than one personality traits measures relied solely on univariate associations to make inferences about convergent validity (e.g. Hong et al., 2008; Paunonen, 2003). According to Thompson (2000) canonical correlation as a type of multivariate technique not only reduces type I error but it can also better approximate the reality of the human behavior. The redundancy index showed that the shared variance between BFI and IPIP is 48\%-49\%. Although the two personality measures have a considerable percent of variance in common, there is another $51-52 \%$ of unexplained variance. In a meta-analytic study on the convergent validity of various personality scales, authors heavily questioned the instruments commensurability (Pace \& Brannick, 2010). In fact, they pointed out that the convergent validities were lower than it was expected. Hence, it is not surprising that depending on the instrument used, different conclusions about the impact of personality traits on computer addiction and internet usage may be reached. The reasons for these differences may include respondent's different interpretations of the item content or add to the evidence that different measures of the same theory may not be entirely equivalent.

\section{Conclusions}

In summary, the results of this study showed that two different measures of the Big Five factors of personality could predict a considerable amount of variance in excessive computer and internet use. Thus, personality traits seem to be helpful in understanding technological addictive behaviors. However, the pattern and the relationships of the significant associations were not consistent but varied depending on the personality instrument used and/or the criterion variable. These differences may be partly attributed to moderate levels of convergent validity between the two measures of personality traits. Researchers should be aware of the possible fluctuations in findings when they study the effect of personality traits on computer and excessive internet use.

\section{References}

Andreassen, C. S., Billieux, J., Griffiths, M. D., Kuss, D. J., Demetrovics, Z., Mazzoni, E., \& Pallesen, S. (2016). The relationship between addictive use of social media and video games and symptoms of psychiatric disorders: A large-scale cross-sectional study. Psychology of Addictive Behaviors, 30, 252-262. https://doi.org/10.1037/adb0000160

Baltzis, A., Manolika, M., \& Gardikiotis, A. (2012, May). The 'nobody knows' property: Understanding the uncertainties of cultural consumption. Paper presented at the $10^{\text {th }}$ World Media Economics \& Management Conference, Thessaloniki, Greece. 


\section{MInstitute Macrothink $_{\text {Int }}$}

International Journal of Social Science Research

ISSN 2327-5510

2019, Vol. 7, No. 2

Bratter, T. E., \& Forrest, G. G. (1985). Alcoholism and substance abuse: Strategies for clinical intervention. New York: Free Press.

Buckner, J. E. V., Castille, C. M., \& Sheets, T. L. (2012). The five factor model of personality and employees' excessive use of technology. Computers in Human Behavior, 28, 1947-1953. https://doi.org/10.1016/j.chb.2012.05.014

Buffardi, L. E., \& Campbell, W. K. (2008). Narcissism and social networking web sites. Personality and Social Psychology Bulletin, 34, 1303-1314. https://doi.org/10.1177/0146167208320061

Carpenter, B. D., \& Buday, S. (2007). Computer use among older adults in a naturally occurring retirement community. Computers in Human Behavior, 23, 3012-3024. https://doi.org/10.1016/j.chb.2006.08.015

Caspi, A., \& Roberts, B. W. (1999). Personality continuity and change across the life course. In L. A. Pervin \& O. P. John (Eds.), Handbook of personality: Theory and research (pp. 300-326). New York: Guilford Press.

Costa, P. T., \& McCrae, R. R. (1992). Four ways five factors are basic. Personality and Individual Differences, 13, 653-665. https://doi.org/10.1016/0191-8869(92)90236-I

Digman, J. M. (1989). Five robust trait dimensions: Development, stability, and utility. Journal of Personality, 57, 195-214. https://doi.org/10.1111/j.1467-6494.1989.tb00480.x

Doherty, J. M. (2002). A survey of computer use in the New Zealand building and construction industry. Journal of Information Technology in Construction, 2(4), 73-86.

Ehrenberg, A., Juckes, S., White, K. M., \& Walsh, S. P. (2008). Personality and self-esteem as predictors of young people's technology use. Cyberpsychology \& Behavior, 11, 739-741. https://doi.org/10.1089/cpb.2008.0030

Fossati, A., Borroni, S., Marchione, D., \& Maffei, C. (2011). The big five inventory (BFI). European Journal of Psychological Assessment, 27, 50-58. https://doi.org/10.1027/1015-5759/a000043

Glass, R., Li, A., \& Rong, P. (2014). Personality, problematic social network use and academic performance in China. Journal of Computer Information Systems, 54, 88-96. https://doi.org/10.1080/08874417.2014.11645726

Goldberg, L. R. (1990). An alternative "description of personality": The big-five factor structure. Journal of Personality and Social Psychology, 59, 1216-1229. https://doi.org/10.1037/0022-3514.59.6.1216

Goldberg, L. R., Johnson, J. A., Eber, H. W., Hogan, R., Ashton, M. C., Cloninger, C. R., \& Gough, H. G. (2006). The international personality item pool and the future of public-domain personality measures. Journal of Research in Personality, 40, 84-96. https://doi.org/10.1016/j.jrp.2005.08.007 
Gombor, A., \& Vas, L. (2008). A nation-and gendered-based study about the relationship between the Big Five and motives for Internet use: A Hungarian and Israeli comparison. Theory and Science, 10, 1-6.

Griffiths, M. (1995). Technological addictions. Clinical Psychology Forum, 76, 14-19. Retrieved from http://irep.ntu.ac.uk/id/eprint/23863

Griffiths, M. (2000). Does Internet and computer “addiction" exist? Some case study evidence. CyberPsychology \& Behavior, 3, 211-218. https://doi.org/10.1089/109493100316067

Guadagno, R. E., Okdie, B. M., \& Eno, C. A. (2008). Who blogs? Personality predictors of blogging. Computers in Human Behavior, 24, 1993-2004. https://doi.org/10.1016/j.chb.2007.09.001

Hong, R. Y., Paunonen, S. V., \& Slade, H. P. (2008). Big Five personality factors and the prediction of behavior: A multitrait-multimethod approach. Personality and Individual Differences, 45, 160-166. https://doi.org/10.1016/j.paid.2008.03.015

John, O. P., \& Srivastava, S. (1999). The big five trait taxonomy: History, measurement, and theoretical perspectives. In L. A. Pervin \& O. P. John (Eds.), Handbook of personality: Theory and research (pp. 102-138). New York: Guilford.

Kayiş, A. R, Satici, S., A., Yilmaz, M., F., Şimsek, D., Ceyhan, E., \& Bakioğlu, F. (2016). Big five-personality trait and internet addiction: A meta-analytic review. Computers in Human Behavior, 63, 35-40. https://doi.org/10.1016/j.chb.2016.05.012

Landers, R. N., \& Lounsbury, J. W. (2006). An investigation of Big Five and narrow person personality traits in relation to Internet usage. Computers in Human Behavior, 22, 283-293. https://doi.org/10.1016/j.chb.2004.06.001

Marcus, B., Machilek, F., \& Schütz, A. (2006). Personality in cyberspace: Personal websites as media for personality expressions and impressions. Journal of Personality and Social Psychology, 90, 1014-1031. https://doi.org/10.1037/0022-3514.90.6.1014

Pace, V. L., \& Brannick, M. T. (2010). How similar are personality scales of the "same" construct? A meta-analytic investigation. Personality and Individual Differences, 49, 669-676. https://doi.org/10.1016/j.paid.2010.06.014

Paunonen, S. V. (2003). Big Five factors of personality and replicated predictions of behavior. Journal of Personality and Social Psychology, 84, 411-424. https://doi.org/10.1037/0022-3514.84.2.411

Paunonen, S. V., \& Ashton, M. C. (2001). Big Five predictors of academic achievement. Journal of Research in Personality, 35, 78-90. https://doi.org/10.1006/jrpe.2000.2309

Shapira, N. A., Goldsmith, T. D., Keck, P. E., Khosla, U. M., \& McElroy, S. L. (2000). Psychiatric features of individuals with problematic internet use. Journal of Affective Disorders, 57, 267-272. https://doi.org/10.1016/S0165-0327(99)00107-X 


\section{Macrothink}

International Journal of Social Science Research

ISSN 2327-5510

2019, Vol. 7, No. 2

Sherry, A., \& Henson, R. K. (2005). Conducting and interpreting canonical correlation analysis in personality research: A user-friendly primer. Journal of Personality Assessment, 84, 37-48. https://doi.org/10.1207/s15327752jpa8401_09

Siomos, K. E., Floros, G. D., Mouzas, O. D., \& Angelopoulos, N. V. (2009). Validation of adolescent computer addiction test in a Greek sample. Psychiatriki, 20(3), 222-232.

Stewart, D., \& Love, W. A. (1968). A general canonical correlation index. Psychological Bulletin, 70, 160-163. https://doi.org/10.1037/h0026143

Teng, C. I. (2008). Personality differences between online game players and nonplayers in a student sample. CyberPsychology \& Behavior, 11, 232-234. https://doi.org/10.1089/cpb.2007.0064

Thompson, B. (2000). Canonical correlation analysis. In G. G. Laurence \& P. R. Yarnold (Eds.), Reading and Understanding more Multivariate Statistics. Washington, DC: American Psychological Association.

Tsai, H. F., Cheng, S. H., Yeh, T. L., Shih, C. C., Chen, K. C., Yang, Y. C., \& Yang, Y. K. (2009). The risk factors of Internet addiction-a survey of university freshmen. Psychiatry Research, 167, 294-299. https://doi.org/10.1016/j.psychres.2008.01.015

Wang, C. W., Ho, R. T., Chan, C. L., \& Tse, S. (2015). Exploring personality characteristics of Chinese adolescents with internet-related addictive behaviors: Trait differences for gaming addiction and social networking addiction. Addictive Behaviors, 42, 32-35. https://doi.org/10.1016/j.addbeh.2014.10.039

Wilson, K., Fornasier, S., \& White, K. M. (2010). Psychological predictors of young adults' use of social networking sites. Cyberpsychology, Behavior, and Social Networking, 13, 173-177. https://doi.org/10.1089/cyber.2009.0094

Yan, W., Li, Y., \& Sui, N. (2014). The relationship between recent stressful life events, personality traits, perceived family functioning and internet addiction among college students. Stress and Health, 30, 3-11. https://doi.org/10.1002/smi.2490

Young, K. S. (1996). Psychology of computer use: XL. Addictive use of the Internet: a case that breaks the stereotype. Psychological Reports, 79, 899-902. https://doi.org/10.2466/pr0.1996.79.3.899

Young, K. S. (1998). Internet addiction: The emergence of a new clinical disorder. CyberPsychology \& Behavior, 1, 237-244. https://doi.org/10.1089/cpb.1998.1.237

Ypofanti, M., Zisi, V., Zourbanos, N., Mouchtouri, B., Tzanne, P., Theodorakis, Y., \& Lyrakos, G. (2015). Psychometric properties of the International Personality Item Pool Big-Five personality questionnaire for the Greek population. Health Psychology Research, 3, 2206. https://doi.org/10.4081/hpr.2015.2206 


\section{Copyright Disclaimer}

Copyright for this article is retained by the authors, with first publication rights granted to the journal.

This is an open-access article distributed under the terms and conditions of the Creative Commons Attribution license (http://creativecommons.org/licenses/by/3.0/). 